\title{
Does austerity drive public service innovation? Evidence from shared senior management teams in local government
}

\section{Benedetta Bello, James Downe, Rhys Andrews \& Steve Martin}

To cite this article: Benedetta Bello, James Downe, Rhys Andrews \& Steve Martin (2018) Does austerity drive public service innovation? Evidence from shared senior management teams in local government, Public Money \& Management, 38:2, 131-138, DOI: 10.1080/09540962.2018.1407161

To link to this article: https://doi.org/10.1080/09540962.2018.1407161

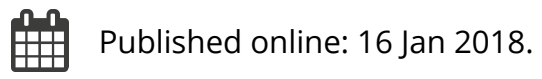

Submit your article to this journal ¿

Џll Article views: 568

Q View related articles ¿

View Crossmark data ${ }^{\top}$

Citing articles: 1 View citing articles $\square$ 


\section{Does austerity drive public service innovation? Evidence from shared senior management teams in local government}

\section{Benedetta Bellò, James Downe, Rhys Andrews and Steve Martin}

Shared senior management teams are a recent and radical response to financial austerity. They aim to improve the efficiency of public services without the disruption, controversy and transaction costs associated with full-blown organizational mergers. This paper assesses the adoption of this management innovation by English district councils, identifies enablers and barriers to its effective implementation, offers a preliminary assessment of its impacts, and draws out practical lessons for policy-makers.

\section{Keywords: Austerity; local government; management innovation; senior management} teams; sharing services.

Since the global financial crisis, governments have introduced comprehensive public sector reforms in order to improve the service provision to their citizens while cutting costs. In the UK, central government has moved away from larger regional structures by placing a greater emphasis on localism (Elcock et al., 2010) and devolving powers and responsibilities downwards. However, the potential of these reforms to deliver a radically different form of local governance has been inhibited by, among other barriers, the political expediency of budget cuts during an era of austerity (Lowndes and Pratchett, 2012). Local government faced significant cuts over the course of the 2010 spending review period (funding has been reduced overall by $33 \%$, with a $10 \%$ reduction in 2015/16 alone) (HM Treasury, 2010). In addition to cutting back provision, councils have responded by seeking to transform the ways in which they manage and deliver services (LGA, 2014).

There is growing evidence that austerity is driving innovation in the public sector (Liddle and Murphy, 2012; Raudla et al., 2013) and innovation is at the top of the policy agenda for governments across the world (Koch and Hauknes, 2005; Windrum, 2008; Wu et al., 2013). Overmans and Noordegraaf (2014) suggest that organizations have responded to austerity in two main ways: fiscal (focusing only on balancing the fiscal budget); and/or organizational (focused primarily on organizational structures and systems with reducing spending as an indirect result).

Recent research has shown that sharing services is becoming increasingly common and is seen as a way to increase efficiency and improve services by reducing surplus capacity and areas of duplication (Raudla and Tammel, 2015). However, despite the widespread enthusiasm, various downsides and problems in their implementation have been unveiled in different countries (for example the UK, Belgium, Australia, the Netherlands) (Elston and MacCarthaigh, 2016). Empirical evidence about the enablers and impacts of sharing services is still lacking, partly because of a lack of robust evaluation and also because many initiatives are still in their infancy (Elston and MacCarthaigh, 2016).

Sharing senior management teams (SMTs) is a recent management innovation that occurs when a team of senior managers oversee two or more public organizations. It often starts with a shared chief executive before moving on to sharing the whole senior management team. Shared SMTs are an attractive option for councils and other public organizations seeking to save money without the upheaval, controversy and transactions costs associated with full-blown mergers. They involve a high degree of organizational integration which reduces management costs and gains economies of scale without the loss of organizational identity and sovereignty. The sharing of SMTs
Benedetta Bellò is a Research Associate at the Centre for Local E Regional Government Research, Cardiff Business School, $U K$.

James Downe is a Professor in Public Policy E

Management at Cardiff Business School and Director of Research at the Wales Centre for Public Policy, UK.

Rhys Andrews is a Professor of Public Management at Cardiff Business School.

Steve Martin is a Professor of Public Policy E

Management at Cardiff Business School and Director of the Wales Centre for Public Policy. 
can be seen as continuing a long tradition of local adaptability to centrally-imposed change (John, 2014).

Evaluation of the use of shared SMTs by councils can help to clarify the enablers and barriers to this type of innovation, and may offer lessons for policy-makers interested in disseminating best practice across the public sector. In an era of 'super headteachers', shared management of Clinical Commissioning Groups (CCGs), blue light (emergency) services integration and collaborative procurement, the experience of local government in sharing SMTs can yield invaluable insights about the limits and potential of this type of innovation in the public sector.

England is largely covered by a two-tier local government system: county councils are responsible for strategic services (for example social services and education) and 201 lowertier district councils provide neighbourhood services, such as waste collection, leisure centres and social housing. This paper presents the results of an in-depth analysis of shared SMTs in English district councils. Drawing on qualitative research, it identifies the main enablers and barriers to councils setting up these arrangements and offers an initial assessment of the types of impacts which they have produced. The findings contribute new knowledge in an emerging area of public sector management and have potential to help develop theory and improve the policy and practice of public service innovation more widely.

\section{Shared senior management teams as a management innovation}

Management innovation (MI) is defined as the introduction of a new structure, process, system, programme, or practice in an organization or its units which 'changes how managers do what they do' (Hamel, 2006, p. 75). MI is distinct from product, service, or technological innovation insofar as these focus on new products or services introduced to meet an external user need (Damanpour and Aravind, 2011).

MIs can improve organizational efficiency and effectiveness, because they are typically aimed at enhancing the managerial capacity and ability to learn that is required to adapt successfully to (changes in) the organizational environment (Damanpour et al., 2009). Critically, such capacity may hold the key to improved service delivery performance in the public sector (Andrews and Boyne, 2010). Indeed, for the past two decades, public service reform programmes across the world have emphasized the need for public organizations to pilot new and innovative management arrangements in order to respond to the pressing problems of our times (Brown et al., 2016).

Within this context, shared SMTs have emerged as an example of a distinctively public sector MI. Although strategic alliances between private firms are commonplace, they do not entail the appointment of a single chief executive or shared senior management because of the ownership structure of the partners. Hence, while little is known about the drivers and impacts of MIs in general (Birkinshaw et al., 2008; Walker et al., 2011), there is currently no established theory or evidence base on the sharing of SMTs.

The MI literature provides two key perspectives which are helpful in understanding the motivations behind councils' adoption and implementation of shared SMTs. From a rational perspective, sharing a SMT may result in efficiency gains. Councils sharing SMTs are responding to budgetary pressures by exploring alternative service delivery and management models in pursuit of cost savings that enable them to protect 'frontline' services while balancing their budgets. From an institutional perspective, councils may choose to share a SMT because it is perceived to enhance their legitimacy in the eyes of key stakeholders (Walker et al., 2015). The literature suggests that early adopters of a managerial innovation are more likely to seek efficiency gains, whereas later adopters seek legitimacy when adopting managerial innovations (Tolbert and Zucker, 1983; Westphal et al., 1997). Political ideology can also be seen as an institutional motivation for sharing SMTs. Councils led by Conservative administrations tend to be pro-market and may be more inclined to support management innovation than those led by left-wing parties that traditionally prefer hierarchical models of service planning and delivery by in-house teams (Picazo-Tadeo et al., 2012).

The academic literature identifies a large number of enablers of MI at different levels: the environmental level (for example the context, involvement in networks), organizational level (for example slack resources, leadership), innovation level (for example complexity of the innovation) and individual level (for example creativity of employees) (de Vries et al., 2015). Within local government, the importance of having a clear strategic vision and communication have also been shown to be the key factors in accelerating innovation (Munro, 2015). Figure 1 summarizes 
key factors which the literature suggest are related to $\mathrm{MI}$.

In the remainder of the paper, we present the findings from in-depth qualitative research investigating the dynamics of shared SMTs in English local government which tests the extent to which these factors are evident. We start by explaining our methodology before analysing the main motivations behind the decision to share SMTs. We then consider the enablers of and barriers to this innovation, and highlight its impacts to date. We conclude by discussing the implications of these findings for both future research and for practice.

\section{Methodology}

This paper utilizes evidence from three sources. First, we conducted a documentary analysis of council reports, business plans, and minutes from meetings at which the decision to share SMTs were taken. We supplemented this evidence with reports from the Local Government Association (LGA) and local media cuttings to construct a qualitative dataset of all of the shared SMTs that have been introduced by district councils in England. Second, we contacted, by phone, all the English district councils that have shared SMTs to collect information on the main characteristics of these arrangements (including when and why they were set up, the model of sharing that has been adopted, and the impacts to date). Third, we conducted semi-structured interviews with 12 key stakeholders who have played an important role in supporting the introduction and implementation of shared SMTs in English local government. We interviewed representatives from the Department for Communities and Local Government (DCLG), SOLACE (the representative body for local authority chief executives and senior managers working in the public sector in the UK), the LGA, the District Council Network, the Shared Management Council Network, the Shared Service Architects, and five retired council chief executives who had direct experience of shared SMTs.

Interviews were conducted between September and December 2016 and lasted 3060 minutes. They were audiotaped and transcribed in full. The interviews were analysed and coded by keywords and themes, which enabled us to capture the qualitative richness of the phenomenon (Boyatzis, 1998). Interviewees were asked questions about three main areas that were informed by the literature and the framework set out in figure 1. First, questions examined where the impetus for councils to share SMTs came from, what were the main motivations behind the decision to share, and what role was played by central government and other agencies/institutions (for example DCLG, LGA) in incentivizing or supporting the sharing arrangements. Second, questions explored the main enablers and barriers that influenced the decision to share. Third, we asked interviewees about the shortand long-term impacts of sharing SMTs, and their views about the future prospects for this innovation.

\section{Findings}

Our documentary analysis revealed that there were 18 cases of shared chief executives and

Figure 1. Key factors of management innovation.

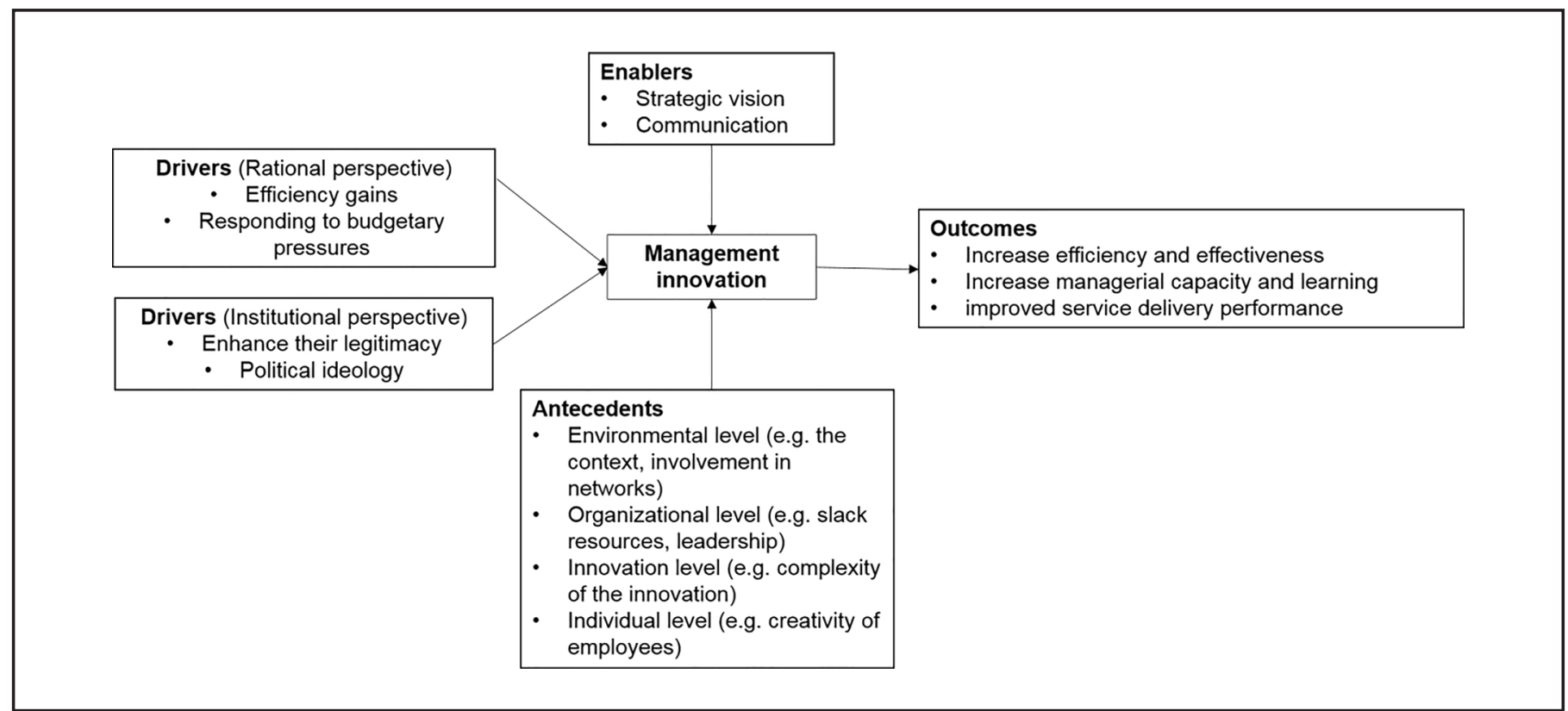


SMTs in English district councils. These arrangements involved 37 councils (one included three councils: North Dorset, West Dorset and Weymouth \& Portland). The majority of shared SMTs had been introduced by councils in the south of England and were led by Conservative administrations. Most were contiguous but four were in non-neighbouring councils and different counties. Interestingly, there were also a number of cases of councils under different political control sharing SMTs, one of which had been in existence for almost a decade (see table 1 for details). There were two cases where councils had decided to move on from shared SMTs to full mergers: West Somerset and Taunton Deane councils in September 2016, and Waveney and Suffolk Coastal agreed to merge in January 2017. Other councils are planning to follow this path to merger, while Dorset is considering creating two unitary authorities from the nine current councils in the county. We also found examples of district councils coming out of joint approaches (for example East Devon and South Somerset, Richmondshire and Hambleton, Great Yarmouth and North Norfolk).

While our focus was on district councils, there were also cases of councils from different tiers of local government working together (for example Essex County Council and Brentwood District Council), as well as cases from unitary arrangements (for example the London boroughs of Westminster, Hammersmith \&
Fulham and Kensington and Chelsea currently form the tri-borough arrangement but is in the process of being disbanded).

Our research showed considerable variation in how councils organized their shared SMT. The size and structure of shared SMTs differed across the 18 cases. The number of directors varied from one to four, and the number of heads of service range from three to 17 . There are cases of councils that use an 'executive directors' model' where there is no chief executive but the councils are managed by senior directors (for example South Hams and West Devon).

\section{Motivation}

The documentary analysis and interview data showed that one of the main reasons behind the decision to introduce a shared SMT was a response to austerity. Councils regarded shared SMTs as an opportunity to save money by reducing the number of senior managerial posts. The former chief executive of one of the early adopters explained: 'With the management restructure, we went from 17 to nine managers; it helps to present a balanced budget and save money' (Interviewee 3).

Agovernment official explained: 'Austerity, making savings and budgets, that is what is driving a lot of the efficiencies in local government' (Interviewee 6).

Some interviewees believed that the political control of councils made some difference to

Table 1. Shared senior management teams in English district councils.

\begin{tabular}{|c|c|c|c|}
\hline & Political control & Region/county & $\begin{array}{l}\text { Start of sharing } \\
\text { arrangements }\end{array}$ \\
\hline Adur-Worthing & Conservative & West Sussex & 2005 \\
\hline \multirow[t]{2}{*}{ Babergh-Mid Suffolk } & Conservative/ & & \\
\hline & No overall control & Suffolk & 2011 \\
\hline Bolsover-North East Derbyshire & Labour & Derbyshire & 2011 \\
\hline Breckland-South Holland & Conservative & Norfolk/Lincolnshire & 2010 \\
\hline Bromsgrove-Redditch & Conservative/Labour & Worcestershire & 2008 \\
\hline Cotswold-West Oxfordshire & Conservative & Gloucestershire/Northamptonshire & 2008 \\
\hline Cherwell-South Northamptonshire & Conservative & Oxfordshire/Northamptonshire & 2010 \\
\hline Chiltern-South Bucks & Conservative & Buckinghamshire & 2012 \\
\hline East Dorset-Christchurch & Conservative & Dorset & 2010 \\
\hline East Hampshire-Havant & Conservative & Hampshire & 2009 \\
\hline Forest Heath-St Edmundsbury & Conservative & Suffolk & 2012 \\
\hline Staffordshire Moorlands-High Peak & Conservative & Derbyshire/Staffordshire & 2008 \\
\hline Wychavon-Malvern Hills & Conservative & Worcestershire & 2014 \\
\hline \multicolumn{4}{|l|}{ North Dorset-West Dorset- } \\
\hline Weymouth \& Portland & Conservative & Dorset & $2010 * / 2015^{* *}$ \\
\hline South Hams-West Devon & Conservative & Devon & 2007 \\
\hline \multicolumn{4}{|l|}{ South Oxfordshire-Vale of the } \\
\hline White Horse & Conservative & Oxfordshire & 2008 \\
\hline Waveney-Suffolk Coastal & Conservative & Suffolk & 2008 \\
\hline \multirow[t]{2}{*}{ West Somerset-Taunton Deane } & Conservative/ & & \\
\hline & No overall control & Somerset & 2014 \\
\hline
\end{tabular}

*Between West Dorset and Weymouth \& Portland. **Between West Dorset, Weymouth \& Portland and North Dorset. 
whether councils decided to share the chief executive and the SMT. One reported: 'Labour councils have a more paternalistic approach. They want to have control and have more insourcing activities. Conservative councils prefer outsourcing and shared services' (Interviewee 2).

As noted above, our documentary analysis confirmed that a large majority of arrangements were between Conservative-controlled councils (see table 1 for details). Rather than parties simply having different ideological perspectives towards shared services/management, one interviewee believed that the decision to introduce a shared SMT was aimed at preventing senior management stepping into the political realm: "It does take the management out of the political space and, at least in theory, creates a clearer line on where management starts and finishes...It was strongly used by Conservative politicians around the 2010 election because, especially in the New Labour years, public management has overstepped into the political world' (Interviewee 5).

Another motivation for councils to share senior managers was the opportunity, through the integration of staff, to have access to a wider range of expertise (for both managers and politicians) and to become more resilient: 'You need to make sure that you have access to all the specialist expertise you need. It gives you a bit more resilience and gives you that wider opportunity of, if another council has got expertise that you're missing then you've got that opportunity to just have a bit more [of] that kind of knowledge' (Interviewee 6).

The UK government encouraged councils to share senior managers to save money (DCLG, 2012) and suggested councils could also share chief executives and SMTs with other public authorities. As a government official explained: 'We allowed councils to maintain their own freedom of decision-making in their own councils, their identity and sovereignty but with the opportunity to save some cash' (Interviewee 3).

There were no financial incentives in place until the government introduced the Transformation Challenge Award (TCA) in 2014 (which ran until 2016). Part of the funding was devoted specifically to supporting the sharing of chief executives and SMTs. Three sharing arrangements benefitted from this fund: Cotswold and West Oxfordshire (awarded $£ 400,000$ ); Malvern Hills and Wychavon $(£ 400,000)$; and North Dorset, West Dorset and Weymouth \& Portland $(£ 600,000)$. The
TCA was welcomed by those councils which received the funding, but others were concerned by the timing of the incentive. One former chief executive explained: 'For those that were earlier adopters it was a slightly disappointing or frustrating. It was because, from an opportunistic approach, obviously there were quite significant costs for setting up the arrangement...But we don't get any money' (Interviewee 4).

Interviewees also complained that central government's interest in shared SMTs seemed to have varied over time: 'The central government approach has not been consistent. In the previous administration, there was a clear vision for districts to share chief executives and SMT. There is reticence at the moment to enforce shared SMTs' (Interviewee 4).

\section{Enablers}

One of the main enablers of shared SMTs was that councils entering into these arrangements saw themselves as similar or facing similar challenges. As described above, party politics was important: 'The combination of leadership between councils (Tory-Tory is easier), the degree of which they are open or ready to share some services' (Interviewee 1).

But this is only the starting point. It is also important that the two (or three) leaders get on well at a personal level and trust each other. They need to be willing to work together to introduce, implement and drive forward innovation and overcome fear of one council 'taking over' another. One interviewee explained that: 'The initial concern of losing lots of sovereignty begins to dissipate if the political leadership tends to find that they can make the situation work. If they don't get on well, it is not going to work' (Interviewee 1).

There are particular skills needed by politicians in both councils: 'The political leader has to be strong in the sense to be consistent across parties, a strong group because it is not a thing that happens in few months, it takes time in order to happen successfully' (Interviewee 5).

Councils also need a clear shared vision of how to develop the partnership. One interviewee suggested that: 'We had a clear vision on what we were going to do in 4 or 5 years' period, we decided to share everything as soon as we possibly could' (Interviewee 3).

Interviewees talked of the importance of effective communication so that everyone was aware of plans: 'I think some of the enablers were good communication throughout, telling staff what is happening, telling other 
stakeholders what's happening, talking to each other always helps' (Interviewee 6). And: 'When you want to change programmes, you spend time with the people you think you can rely on in order to send the right messages' (Interviewee 3).

The LGA has played a supportive role for councils that are interested in exploring sharing senior managers. It provides a 'knowledge hub' which hosts an open access group for officers and politicians who are involved in, or interested in, shared management arrangements, and it facilitates a 'shared chief executive network' to support chief executives who work for two or more councils. Its role has been to: 'Encourage councils in every kind of circumstances. If they want to explore having shared management functions, we help them, but it is entirely up to them' (Interviewee 1).

A final enabler was the government's invitation to councils in two-tier areas to submit proposals for unitary status or to be pathfinders for new ways of working (DCLG, 2006). Five out of the 18 shared management arrangements included in our analysis were in regions involved in bidding for pathfinder status (councils in Dorset and Suffolk). One of the interviewees suggested that: "If we look at the Suffolk example, they were thinking of a unitary but then the government changed and it stopped the process, but they were already working together' (Interviewee 5).

It seems that the time spent on developing new ways of working has benefits when considering shared management arrangements a few years later.

\section{Barriers}

The main barriers that can hinder the introduction of this kind of innovation are perceived to be problems caused by cultural differences between the councils and internal resistance to change. We heard from a number of interviewees how introducing change is made harder when there are cultural differences between organizations. One explained that: 'If you have got two different organizations, you need an amount of time and energy to manage two different processes and procedures, different political cultures' (Interviewee 5).

Other interviewees pointed to the difficulties that some managers have in adapting to change: 'When you crash two management teams in one and you realize you are working for two councils, some people physically can't cope with it. One minute you are wearing this hat, the next minute, another hat' (Interviewee 4).
Politicians also need to adapt to a new environment in which they have less day-today contact with senior officers: 'The main barrier is tradition. A culture that says "Since I've been a councillor, we've always had our own chief executive and to be honest, I don't want to lose that. I want access to the chief executive directly all the time"' (Interviewee 7).

A final barrier is the set-up costs of shared SMTs, especially where redundancies are involved. In South Hams and West Devon councils, for example, the decision to share the SMT was gradually implemented starting in 2007. Between 2011 and 2014, the number of staff on the senior management team was cut from 15 to five, plus one S151 officer (see table 2 for details). While the costs of this restructuring were recovered in less than three years, other councils struggled to find the resources needed to make the necessary upfront 'investment' in restructuring.

\section{Impacts and future of shared SMT}

All participants in our research agreed that the main impact to date of shared SMTs had been to cut costs: 'It's a question of savings and maintaining these savings. You reach a point of non-return. Many councils are afraid of splitting because of that' (Interviewee 2).

However, our evidence suggests that the savings councils can make through sharing SMTs are relatively modest. The average savings were around $£ 300,000$ per year, ranging from councils making annual savings of just $£ 100,000$ per year to those that saved around $£ 1$ million.

Beyond the financial impacts, interviewees reported greater flexibility and resilience to face future challenges as benefits of having adopted shared SMTs, but these impacts are often unquantifiable: 'Greater resilience, a change in the organizational culture, the alignment of workforces, higher SMTs' capacity and capability to do things more than professionals: what they have achieved and the culture they have developed in terms of collaboration and transformation' (Interviewee 1).

There can also be a positive impact on individuals: 'There were new opportunities to be involved in new projects, from a career point of view to acquire new skills and generate enthusiasm. Some people have been revitalized' (Interviewee 3).

The introduction of a shared chief executive was often part of a broader, sometimes incremental, process. In many cases, councils shared chief executives first and adopted a 
Table 2. Restructuring costs and savings in South Hams District Council and West Devon Borough Council.

\begin{tabular}{lll}
\hline & 2011 & 2014 \\
\hline $\begin{array}{l}\text { People in SMT } \\
\text { Restructuring costs }\end{array}$ & 15 & 5 \\
Savings per year & Approximately $£ 1$ million & $\begin{array}{l}\text { Approximately } £ 0.5 \text { million } \\
\text { Approximately } £ 200,000\end{array}$ \\
\hline
\end{tabular}

shared SMT later. Some councils with shared SMTs were sharing every service while others had opted for a pragmatic approach with a mixed economy of services provision, sharing different services with a range of different councils. In cases where every service was being shared, the natural progression would be a merger, but the majority had not proceeded towards this wanting, instead, to retain their independence, identity and sovereignty: ' $\mathrm{XXX}$ and XXX are merged in any other name but they can't merge politically' (Interviewee 1).

\section{Conclusions}

This paper provides an analysis of the current state of the art of shared SMTs in English district councils. The findings suggest that the main motivation behind the decision to share a SMT comes from a rational perspective (Walker et al., 2015) and is cost-based.

While recent research has suggested that austerity management tends to deliver solutions that are not innovative (Overmans and Noordegraaf, 2014), our findings show that a shared SMT is a local innovative response that helps to protect front-line services while cutting costs. Given that financial pressures are likely to intensify as councils seek to cope with the withdrawal of the Revenue Support Grant in 2020 , there is potential for others to adopt this type of innovation.

In addition to savings, councils also point to a range of non-financial benefits of shared SMTs including increased organizational resilience and access to new expertise and learning. Shared management arrangements are perceived by those councils that are involved in them as a better option than local government reorganization which would see them absorbed by larger organizations. Shared SMTs enable small district councils to retain their own identity and a degree of freedom to respond to local priorities.

The emergence of shared SMTs is significant given the inherent internal resistance to change and demonstrates that significant MI is possible even in difficult circumstances. Key enablers include strong and consistent political leadership, a clear and shared vision of the future, an openness to new ways of working and a clear communication strategy toward internal and external stakeholders.

Our findings revealed relatively modest savings for councils that were sharing a SMT, but they indicate that senior managers can work across two or more organizations and this has the potential to improve efficiency and effectiveness (Damanpour et al., 2009) and develop resilience to face future financial challenges.

The future of shared SMTs is not easy to predict due to the fast-changing policy landscape with the addition of devolution deals, combined authorities and the prospect of new unitary authorities. There is also some uncertainty about whether central government will encourage and support such arrangements in the future, let alone whether the enthusiasm of districts to introduce this MI can be sustained. There is value in tracking developments over time to see whether existing shared SMTs remain viable or extend their arrangements to include working with other councils or other public service providers, such as health trusts and police forces. There is also a need for further research which examines quantitatively the impact of shared SMTs on service outcomes.

\section{Acknowledgements}

This paper is part of a project (called TROPICO) that has received funding from the European Union's Horizon 2020 research and innovation programme under grant agreement No. 726840 .

\section{References}

Andrews, R. and Boyne, G. A. (2010), Capacity, leadership, and organizational performance: testing the black box model of public management. Public Administration Review, 70, 3, pp. 443-454.

Australian Public Service Commission (2013), State of the Service Report (https:// www.apsc.gov.au/_data/assets/pdf_file/0003/ 64362/SoSR-2013-14-web.pdf).

Birkinshaw, J., Hamel, G. and Mol, M. J. (2008), Management innovation. Academy of Management Review, 33, 4, pp. 825-845.

Boyatzis, R. (1998), Qualitative Information: Thematic Analysis and Code Development (Sage). 


\section{IMPACT}

Our findings provide an analysis of the state of the art of shared SMTs in English district councils. It shows the motivations for introducing this management innovation and that a shared SMT can increase resilience, capacity, and internal competences. While evidence on shared services across the world shows that these types of innovation are not always a guaranteed success (for example Australian Public Service Commission, 2013), shared SMTs have proven their usefulness in making savings by reducing senior management. Policy-makers should consider incentivizing shared SMTs and developing training activities that can help managers overcome the challenges of managing more than one 'sovereign' organization.
Brown, L., Osborne, S. P. and Walker, R. M. (Eds), (2016), Innovation in Public Services (Routledge).

Damanpour, F. and Aravind, D. (2011), Managerial innovation: conceptions, processes, and antecedents. Managementand Organization Review, 8, 2, pp. 423-454.

Damanpour, F., Walker, R. M. and Avellaneda, C. N. (2009), Combinative effects of innovation types and organizational performance. Journal of Management Studies, 46, 4, pp. 650-675.

DCLG (2006), Invitation to all Councils in England to Submit Proposals for Future Unitary Structures, to Pioneer, as Pathfinders, New Two-Tier Models.

DCLG (2012), 50 Ways to Save: Examples of Sensible Savings in Local Government.

de Vries, H., Bekkers, V. and Tummers, L. (2015), Innovation in the public sector: a systematic review and future research agenda. Public Administration, 94, 1, pp. 146-166.

Elcock, H., Fenwick, J. and McMillan, J. (2010), The reorganization addiction in local government: unitary councils for England. Public Money E Management, 30, 6, pp. 331338.

Elston, T. and MacCarthaigh, M. (2016), Sharing services, saving money? Five risks to cost-saving when organizations share services. Public Money E Management, 36, 5, pp. 349-356.

Hamel, G. (2006), The why, what and how of managementinnovation. Harvard Business Review, 84, 2, pp. 72-84.

HM Treasury (2010). Spending Review 2010. Cm 7942 (The Stationery Office).

John, P. (2014), The great survivor: the persistence and resilience of English local government. Local Government Studies, 40, 5, pp. 687-704.

Koch, P. and Hauknes, J. (2005), Innovation in the Public Sector. Public Report No. D20 (NIFU STEP).
LGA (2014), Transforming Local Public Services using Technology and Digital Tools and Approaches.

Liddle, J. and Murphy, P. (2012), Public administration in an era of austerity. Public Money E Management, 32, 2, pp. 83-86.

Lowndes, V. and Pratchett, L. (2012), Local governance under the coalition government: austerity, localism and the 'Big Society'. Local Government Studies, 38, 1, pp. 21-40.

Munro, J. (2015), Accelerating innovation in local government. Public Money E Management, 35, 3, pp. 219-226.

Overmans, J. F. A. and Noordegraaf, M. (2014), Managing austerity: rhetorical and real responses to fiscal stress in local government. Public Money E Management, 34, 2, pp. 99-106.

Picazo-Tadeo, A. J. et al. (2012), Do ideological and political motives really matter in the public choice of local services management? Evidence from urban water services in Spain. Public Choice, 151, 1, pp. 215-228.

Raudla, R., Savi, R. and Randma-Liiv, T. (2013), Literature Review on Cutback Management (www.cocops.eu).

Raudla, R. and Tammel, K. (2015), Creating shared service centres for public sector accounting. Accounting, Auditing E Accountability Journal, 28, 2, pp. 158-179.

Tolbert, P. S. and Zucker, L. G. (1983), Institutional sources of change in the formal structure of organizations: the diffusion of civil service reform, 1880-1935. Administrative Science Quarterly, 28, 1, pp. 22-39.

Walker, R. M., Avellaneda, C. N. and Berry, F. S. (2011), Exploring the diffusion of innovation among high and low innovative localities. Public Management Review, 13, 1, pp. 95-125.

Walker, R. M., Chen, J. and Aravind, D. (2015), Management innovation and firm performance: an integration of research findings. European Management Journal, 33, 5, pp. 407-422.

Westphal, J. D., Gulati, R. and Shortell, S. M. (1997), Customization or conformity? An institutional and network perspective on the content and consequences of TQM adoption. Administrative Science Quarterly, 42, 2, pp. 366394.

Windrum, P. (2008), Innovation and entrepreneurshipin public services. In Windrum, P. and Koch, P. (Eds), Innovation in Public Sector Services-Entrepreneurship, Creativity and Management (Edward Elgar).

Wu, J., Ma, L. and Yang, Y. (2013), Innovation in the Chinese public sector: typology and distribution. Public Administration, 91, 2, pp. 347-365. 